\title{
Changes in serum LDL, PCSK9 and microRNA-122 in patients with chronic HCV infection receiving Daclatasvir/Asunaprevir
}

\author{
TATSUKI ICHIKAWA ${ }^{1-3}$, HISAMITSU MIYAAKI ${ }^{4}$, SATOSHI MIUMA $^{4}$, NAOTA TAURA ${ }^{4}$, \\ YASUHIDE MOTOYOSHI ${ }^{1}$, HIROSHI AKAHOSHI ${ }^{1}$, JUNPEI NAKAMURA ${ }^{2}$, YOUICHI TAKAHASHI ${ }^{2}$, \\ TETSUROU HONDA ${ }^{1}$, HIROYUKI YAJIMA ${ }^{1}$, RYOUHEI UEHARA ${ }^{1}$, NAOYUKI HINO ${ }^{3,4}$, \\ SYOUHEI NARITA $^{1}$, HISAYA TANAKA ${ }^{1}$, SEINA SASAKI ${ }^{1}$ and KAZUHIKO NAKAO ${ }^{4}$ \\ ${ }^{1}$ Department of Gastroenterology; ${ }^{2}$ Innovation and Translational Research Center, Nagasaki Harbor Medical Center, \\ Nagasaki 850-8555; Departments of ${ }^{3}$ Comprehensive Community Care Systems, and ${ }^{4}$ Gastroenterology and \\ Hepatology, Graduate School of Biomedical Sciences, Nagasaki University, Nagasaki 852-8523, Japan
}

Received May 15, 2018; Accepted January 11, 2019

DOI: $10.3892 /$ br.2019.1189

\begin{abstract}
The present study evaluated the changes in lipid profile, and the associations between serum protein convertase subtilisin/kexin 9 (PCSK9), microRNA (miR)122 and low-density lipoprotein variation following treatment of hepatitis $\mathrm{C}$ virus (HCV) genotype $1 \mathrm{~b}$ infection with Daclatasvir/Asunaprevir. A total of 39 patients with HCV genotype $1 \mathrm{~b}$ infection with chronic hepatitis received a 24-week treatment regimen of Daclatasvir/Asunaprevir. Laboratory data were obtained for each subject every 4 weeks during treatment and every 12 weeks after treatment. Serum miR122 and PCSK9 were measured at the start of treatment (week 0), end of treatment (week 24), 4 weeks after the end of treatment (week 28), 12 weeks after the end of treatment (week 36) and 28 weeks after the end of treatment (week 52). LDL was increased at week 4 after the start of treatment to week 52 . The increased LDL/HDL ratio at week 52 compared with week 4 was also associated with relative miR122 at week 52 .
\end{abstract}

Correspondence to: Dr Tatsuki Ichikawa, Department of Gastroenterology, Nagasaki Harbor Medical Center, 6-39 Shinchi, Nagasaki 850-8555, Japan

E-mail: ichikawa@nagasaki-u.ac.jp

Abbreviations: IFN, interferon; BMI, body mass index; FPG, fasting plasma glucose; HbAlc, hemoglobin A1c; HCV1a/1b, hepatitis $\mathrm{C}$ virus genotype $1 \mathrm{a} / \mathrm{lb}$; TG, triglyceride; TC, total cholesterol; HDL-C, high-density lipoprotein cholesterol; LDL-C, low-density lipoprotein cholesterol; LDLR, low-density lipoprotein receptor; HOMA-IR, homeostasis model assessment of insulin resistance; HOMA- $\beta$, homeostasis model assessment of insulin secretion; CPI, C-peptide index; PCSK9-A/I, protein convertase subtilisin/kexin 9-active/inactive; miR, microRNA; DAA, direct acting anti-viral; SVR, sustained viral response; IMT, intima-media thickness

Key words: hepatitis C virus, direct acting anti-virals, low-density lipoprotein, microRNA122, protein convertase subtilisin/kexin 9
At week 4, PCSK9-active form (A) was lower than that at other time points, and PCSK9-inactive form (I) exhibited the greatest increase. At week 52, PCSK9-A was higher than that during treatment, but PCSK9-I level at week 52 did not markedly differ from that any time point except for week 4 . Relative miR122 at week 4 was associated with increased PCSK9-A at weeks 36 and 52 from the start of DAA. In summary, treatment of $\mathrm{HCV}$ with Daclatasvir/Asunaprevir resulted in elevated LDL, and relative miR122 and PCSK9-A levels in serum appeared to have some association with LDL increase.

\section{Introduction}

Hepatitis $\mathrm{C}$ virus (HCV) is a human pathogen responsible for acute and chronic liver disease (1-3). An estimated 130-180 million individuals are infected worldwide (1). HCV induced morbidity and mortality are primarily due to liver complications including liver cirrhosis and hepatocellular carcinoma (3). In addition, many extrahepatic manifestations have been linked to chronic HCV infection with related morbidity and mortality, including cardiovascular disease, type 2 diabetes mellitus, insulin resistance, neurocognitive dysfunction, systemic vasculitis, B cell non-Hodgkin lymphoma and chronic kidney disease $(2,3)$. At present, many parts of the HCV life cycle, including entry into naïve cells, infectivity, RNA replication, viral assembly, viral secretion associated with lipid metabolism $(1,4)$, lipid abnormality and atherosclerosis, are considered of great importance in chronic $\mathrm{HCV}$ infected patients.

Daclatasvir is a selective nonstructural protein $5 \mathrm{~A}$ replication complex inhibitor; asunaprevir is a nonstructural protein 3 protease inhibitor active against $\mathrm{HCV}$ genotypes 1a and 1b (5). In previous study, Daclatasvir was dosed as two 30-mg tablets once-daily (5). Asunaprevir was initially dosed as three 200-mg tablets twice-daily; subsequently, the dose was reduced to 200-mg twice-daily after a clinical study reported the elevation of hepatic enzymes (5). Sustained viral response (SVR) at week 12 after the start of treatment was achieved in $89.9 \%$ of treatment-naïve patients, $84.7 \%$ of interferon (IFN)-ineligible/intolerant 
patients, and $81.9 \%$ of non-responder patients. Furthermore, $89.0 \%$ of IFN-ineligible/intolerant patients and $83.1 \%$ of non-responder patients achieved SVR24, which indicated that Daclatasvir/Asunaprevir provided a highly effective and well-tolerated treatment option for patients with HCV genotype $1 \mathrm{~b}(5,6)$.

In an IFN treatment regime, cases of HCV genotype 2 infection may benefit more from viral clearance via metabolic changes than genotype 1 infections, particularly in those without baseline insulin resistance (7). In an IFN-free treatment regime, HCV genotype 3 suppression during sofosbuvir/ribavirin was indicated to restore distal sterol metabolites, which indicated viral interference with de novo lipogenesis or selective retention by hepatocytes (8). Additionally, clearance of HCV genotype 1 using sofosbuvir/ribavirin previously resulted in a rapid change in peripheral and intrahepatic metabolic pathways, which implicated a direct effect of HCV replication on lipid homeostasis (9). In another study, increase in serum low-density lipoprotein (LDL) concentration at 4 weeks during direct-acting antiviral (DAA) treatment was specifically associated with ledipasvir/sofosbuvir treatment and a decrease of HCV core protein (10).

MicroRNA (miR)122 is considered a key component involved in HCV replication (11) and in cholesterol metabolism $(11,12)$ in hepatocytes. Serum miR122 may also be stored in hepatocytes (13). Protein convertase subtilisin/kexin 9 (PCSK9) is an LDL regulator, which operates through LDL receptor (LDLR) degradation (14), and has been associated with HCV entry into hepatocytes (15-17). In the present study, variation in the lipid profile following treatment of $\mathrm{HCV}$ genotype $1 b$ by Daclatasvir/Asunaprevir was evaluated, along with the association between serum PCSK9, miR122 and the variation in LDL.

\section{Patients and methods}

Patients. A total of 39 successive patients (Table I) with HCV genotype $1 \mathrm{~b}$ infection with chronic hepatitis and compensatory cirrhosis who were admitted for treatment with the DAA regimen, Daclatasvir/Asunaprevir (Bristol-Myers Squibb, Princeton, NJ, USA), at Nagasaki Harbor Medical Center, Nagasaki, Japan were enrolled from June 2014 to November 2016. The exclusion criteria were non compensatory cirrhosis and hemodialysis. Combination therapy with Daclatasvir/Asunaprevir was orally administered for a period of 24 weeks (5). During the treatment period, serum HCV-RNA was examined every 2-4 weeks; following the end of the treatment period, these measurements were collected every 12 weeks. SVR was determined at 24 weeks after the end of treatment. At week 24 after the end of treatment, SVR was achieved in 38 patients. Serum levels of HCV-RNA after 4 weeks of treatment were detected. In the study, 2 patients suffered from diabetes mellitus and were taking oral medication and 2 patients suffered from hypercholesterolemia and were taking statin medication. Patients were observed in the period from the start of treatment to 52 weeks later. Informed consent was obtained from each patient included in the study, and the study protocol conformed to the ethical guidelines of the 1975 Declaration of Helsinki, as evidenced by the approval of the study by the Human Research Ethics
Committee of Nagasaki Harbor Medical Center (approval no. NIRB 1609002).

Laboratory measurements. A total of $10 \mathrm{ml}$ whole blood vena (left or right arm) sample per a patient was collected to analyze sera. To obtain the sera, samples were centrifuged at $102 \mathrm{x} \mathrm{g}$ for $5 \mathrm{~min}$ at room temperature. Laboratory data and anthropometric measurements were obtained for each subject every 4 weeks during treatment and every 12 weeks thereafter. The body mass index (BMI) of each patient was calculated from their weight in $\mathrm{kg}$ divided by the square of their height in meters. Laboratory examinations included assessment of white blood cell count, platelet count, prothrombin time, levels of hemoglobin, C-reactive protein, blood urea nitrogen, creatinine, total protein, albumin, total bilirubin, alanine aminotransferase, $\gamma$-glutamyl transpeptidase, cholinesterase, triglyceride (TG), total cholesterol (TC), high-density lipoprotein cholesterol (HDL-C), LDL cholesterol (LDL-C), fasting plasma glucose (FPG), hemoglobin A1c (HbA1c), insulin and C-peptide. The homeostasis model assessment of insulin resistance [HOMA-IR; FPG $(\mathrm{mg} / \mathrm{dl}) \mathrm{x}$ insulin at time $0(\mu \mathrm{U} / \mathrm{ml}) / 405]$ and homeostasis model assessment of insulin secretion [HOMA- $\beta$; insulin at time $0(\mu \mathrm{U} / \mathrm{ml}) \times 360 / \mathrm{FPG}(\mathrm{mg} / \mathrm{dl})-63]$ were calculated for insulin resistance and insulin secretion, respectively (18). The C-peptide index [CPI; C-peptide (ng/ml) / FPG x100] was determined a marker of $\beta$ cell function (19). TC was calculated using the Friedewald formula [TC=LDL-C+HDL-C+TG/5] (20). $\mathrm{BMI}$, insulin and c-peptide were examined at the start of treatment and 52 weeks after treatment. PCSK9 was measured by ELISA assay (BML, Inc., Tokyo, Japan) (21). The concentration of serum PCSK9 was measured to differentiate the active heterodimer form (PCSK9-A) from the inactive free-fragment form (PCSK9-I). Both forms of PCSK9 were measured at the start of treatment, and at weeks 4, 24, 36 and 52 after treatment in 30 patients with conserved serum.

miR extraction and quantification. Total RNAs including preserved miRNAs were extracted from 200- $\mu$ l serum samples using ISOGEN II (Nippon Gene, Tokyo, Japan). Synthetic miR39 was added to serum samples prior to RNA extraction as an internal control (Applied Biosystems, Foster City, CA, USA). The miR122 obtained by reverse transcription-quantitative polymerase chain reaction was quantified using TaqMan MicroRNA assays [has-miR-122-5p (Assay ID 00245) and cel-miR-39-3p(AssayID000200)AppliedBiosystemsaccording to the manufacturer's protocol. RT was performed using the High-Capacity cDNA Reverse Transcription kit (Applied Biosystems) and was conducted at $16^{\circ} \mathrm{C}$ for $30 \mathrm{~min}, 42^{\circ} \mathrm{C}$ for $30 \mathrm{~min}, 85^{\circ} \mathrm{C}$ for $5 \mathrm{~min}$ and then hold at $4^{\circ} \mathrm{C}$. miR122 expression was calculated by the $2^{-\Delta \Delta \mathrm{Cq}}$ method (22) and normalized to synthetic-miR39 expression in the serum (23). Quantitative PCR kit is TaqMan Micro RNA assays (Applied Biosystems) and DNA polymerase is Taqman Universal Mix II, no UNG (Applied Biosystems). The sequences of primers are follows: Has-miR-122-5p: 5'-UGGAGUGUGACAAUGGUGUUUG-3' and cel-miR-39-3p: 5'-UCACCGGGUGUAAAUCAGCU UG-3'. Th thermocycling conditions were follows: Pre-incubation $95^{\circ} \mathrm{C}$ for $10 \mathrm{~min}$; denaturation, $95^{\circ} \mathrm{C}, 15 \mathrm{sec}$; annealing/extension, $60^{\circ} \mathrm{C}, 60 \mathrm{sec}$; amplification was conducted for 45 cycles. miR122 was measured at the start of treatment, 
Table I. Clinical profile of 39 patients prior to direct acting anti-virals treatment.

\begin{tabular}{lcccr}
\hline Parameter & Total $(\mathrm{n}=39)$ & No change $(\mathrm{n}=22)$ & Upregulation $(\mathrm{n}=17)$ & P-value \\
\hline Age (SD) & $70.92(11.02)$ & $73.09(10.36)$ & $68.12(11.54)$ & 0.1654 \\
Female/male & $25 / 14$ & $15 / 7$ & $10 / 7$ & 0.3432 \\
CH/LC & $25 / 14$ & $13 / 9$ & $12 / 5$ & 0.5722 \\
HCV-RNA (SD) & $5.856(0.92)$ & $5.782(0.95)$ & $5.953(0.90)$ & 0.5731 \\
BMI (SD) & $22.95(4.907)$ & $22.48(4.350)$ & $23.57(5.624)$ & 0.4456 \\
ALT (SD) & $41.90(35.96)$ & $38.86(24.94)$ & $45.82(47.18)$ & 0.5560 \\
Albumin (SD) & $4.054(0.317)$ & $4.045(0.349)$ & $4.065(0.280)$ & 0.8537 \\
Platelet (SD) & $16.74(6.226)$ & $16.32(7.101)$ & $17.28(5.035)$ & 0.6415 \\
LDL (SD) & $101.1(24.92)$ & $100.9(28.52)$ & $101.2(20.46)$ & 0.7056 \\
HDL (SD) & $56.71(17.33)$ & $55.05(12.16)$ & $58.77(22.88)$ & 0.8376 \\
TG (SD) & $110.6(48.71)$ & $101.6(38.27)$ & $121.6(58.49)$ & 0.2336 \\
C-peptide (SD) & $2.390(0.787)$ & $2.310(0.686)$ & $2.487(0.908)$ & 0.7711 \\
FPG (SD) & $103.1(16.94)$ & $101.5(13.37)$ & $105.3(20.92)$ & 0.4557 \\
Insulin (SD) & $10.99(5.359)$ & $11.36(5.854)$ & $10.51(4.774)$ & 0.6289 \\
HbA1c (SD) & $5.536(0.510)$ & $5.514(0.385)$ & $5.565(0.650)$ & 0.7611 \\
\hline
\end{tabular}

The data is presented as mean (SD). The unit of HCV-RNA is $\log \mathrm{IU} / \mathrm{mL}$. The references ranges of clinical parameters in fasting serum were: ALT, 5-40 U/l; albumin, 3.8-5.2 g/dl; male platelet count, 13.1-36.2x104/ 1 ; female platelet count, 13.0-36.9x 104/ $\mu 1 ; \mathrm{LDL}, 70-139 \mathrm{mg} / \mathrm{dl}$; HDL male, 40-86 mg/dl; HDL female, 40-96 mg/dl; TG, 50-149 mg/dl; C-peptide 0.61-2.09 ng/ml; FPG, 70-109 mg/dl; insulin, $1.84-12.2 \mu \mathrm{IU} / \mathrm{ml}$; and HbA1c, 4.6-6.2\%. All laboratory data measurements were conducted following overnight fasting. No significant differences were determined between the no change and upregulation groups. Laboratory result variables were compared using t-tests; female/male and $\mathrm{CH} / \mathrm{LC}$ were analyzed using the $\chi^{2}$ test. $\mathrm{CH}$, chronic hepatitis; LC, liver cirrhosis; HCV, hepatitis C virus; BMI, body mass index; FBG, fasting plasma glucose HDL, high-density lipoprotein; LDL, low-density lipoprotein; TG, triglyceride ALT, alanine aminotransferase; HbA1c, hemoglobin A1c; SD, standard deviation.

and at weeks 4, 24, 36 and 52 after treatment. The miR122 assay provided quantitative analysis.

Statistical analysis. Data were analyzed using StatView 5.0 software (SAS Institute, Inc., Cary, NC, USA). Data is presented mean \pm standard deviation. Laboratory result variables were compared using correlation analysis, t-tests, one way analysis of variance (ANOVA) and $\chi^{2}$-square tests. Multiple comparisons were not performed in the ANOVA. Correlation was evaluated based on Pearson's correlation coefficient. $\mathrm{P}<0.05$ was considered to indicate statistical significance.

\section{Results}

Alterations in lipid profile following DAA. Changes in lipid profile and metabolic parameters in patients over the 52-week treatment period were summarized (Fig. 1). LDL, but not HDL and triglyceride, exhibited increases over the treatment period (Fig. 1A, C and D). Since the LDL/HDL ratio was also increased, DAA treatment affected the lipid profile (Table II). Upregulation of LDL continued to the end of observation at week 52. Patients were categorized in the 'upregulation group' if the LDL at week 52 was equal to, or $10 \%$ greater, than the value at week 0 . All other patients were included in the 'no change group' (Fig. 1B). A total of 17 patients were in the upregulation group and 22 were in the no change group. The clinical characteristics were similar in both groups at week 0 (Table I). One patient of each group on medication for diabetes was in the no-change group and upregulation group, respectively, and the 2 patients on medication for hypercholesteremia were placed in the upregulation group. The number of anti-diabetic and anti-hypercholesteremic drug users were not statistically disproportionate in the groups. BMI and HOMA-IR did not obviously change between weeks 0 and 52 (Fig. 1E and F). HbAlc exhibited marginal increase at week 36 compared with week 0 , but was similar between weeks 52 and 0 (Fig. 1G). LDL, total cholesterol and at week 52 were higher than that at the start of DAA, but glucose metabolic markers (FPG, insulin, C-peptide, HOMA- $\beta$, and CPI) and lipids (HDL and TG) were unchanged at weeks 0,36 and 52 (Table II). HCV-RNA relapse was observed at week 28 after the start of treatment in 1 patient in upregulation group; their LDL levels were 65, 94 and $89 \mathrm{mg} / \mathrm{dl}$ at weeks 0,36 and 52, respectively (data not shown). The difference in LDL cholesterol level after DAA treatment was not measured, since only 2 patients had an LDL value at 1 year after DAA treatment that was lower than $90 \%$ of the value prior to treatment.

Serum miR122 and LDL. Subsequently, the association of serum miR122 with upregulation of LDL by DAA treatment in 30 patients was examined. The miR122 assay provided a quantitative analysis. Relative miR122 at an indicated time represents the increase in expression from the start of treatment. Relative miR122 did not differ at each time point (Fig. 2A), or between the no change and upregulation groups (data not shown). The increase in LDL from week 4 to 52 appeared to be weakly associated with relative miR122 at week 52 (Fig. 2B), and the increase in LDL/HDL ratio from 
A

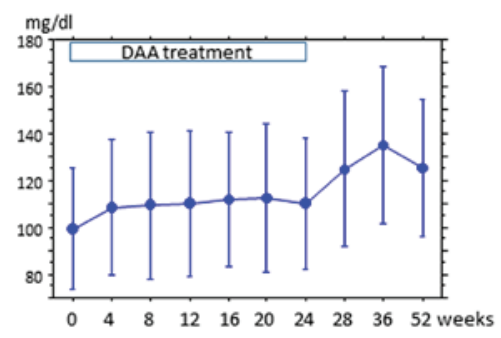

C
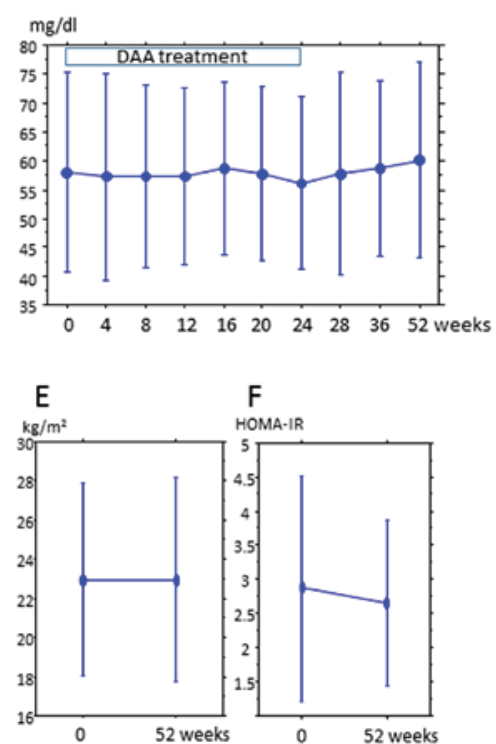

B

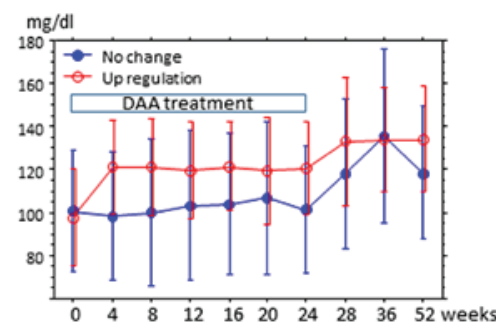

D

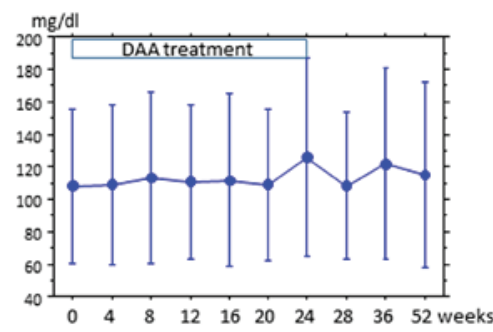

G

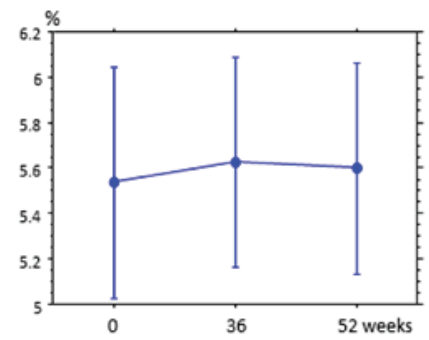

Figure 1. Changes in serum lipids from the start of DAA treatment to 52 weeks after treatment. DAA treatment was terminated after 24 weeks. LDL measurements at weeks 28, 36 and 52 were at weeks 4, 12, and 24 after the end of treatment, respectively. The y-axis is the mean LDL (A and B), HDL (C) and TG (D) concentration $(\mathrm{mg} / \mathrm{dl})$, and the $\mathrm{x}$-axis is the time after the start of treatment. Error bars represent the standard deviation. Differences between time points $(0$ and other time points) were evaluated by a paired t-test, and difference among 0,36 and 52 was evaluated by analysis of variance and $\mathrm{P}<0.05$ were considered statistically significant. (A) Trend of LDL concentration in all patients. LDL at the start of treatment (week 0 ) was significantly lower than that at the other time points (week 4-52) (week 4, $\mathrm{P}=0.0011$, week $8, \mathrm{P}=0.0032$; week 12, $\mathrm{P}=0.0027$; week $16, \mathrm{P}=0.0095$; week $20, \mathrm{P}=0.0037$; week 24, $\mathrm{P}=0.0027$ and weeks 28 -52, $\mathrm{P}<0.0001$ ). LDL at weeks $4,8,12,16,20$ and 24 after treatment was significantly lower than LDL after the end of treatment (weeks 28, 36 and 52; week 4 vs. 28, $\mathrm{P}=0.0004$; week 4 vs. $36-52$, $\mathrm{P}<0.0001$; week 8 vs. $28, \mathrm{P}=0.0007$; week 8 vs. $36-53$, $\mathrm{P}<0.0001$; week 12 vs. $28, \mathrm{P}=0.0006$, week 12 vs. week $36-53$, $\mathrm{P}=0.0001$; week 16 vs. week $28, \mathrm{P}<0.0001$; week 16 vs. week $36, \mathrm{P}=0.0001$; week 16 vs. week 52, $\mathrm{P}=0.0004$; week 20 vs. 28-36; $\mathrm{P}<0.0001$; week 20 vs. week 52, $\mathrm{P}=0.0008$; week 24 vs. 28-36, $\mathrm{P}<0.0001$; week 24 vs. 52, $\mathrm{P}=0.0002$ ). LDL at week 36 after treatment was higher than LDL at week 52 ( $\mathrm{P}=0.0464)$. (B) Trends of LDL concentration in the 'no change' and 'upregulation' groups. In the upregulation group: LDL at week 0 was lower than that at all other time points (weeks 4,8 , $16,28,36$ and 52, $\mathrm{P}<0.0001$; week 12, $\mathrm{P}=0.0003$; week 20 and 24, $\mathrm{P}=0.0002)$; $\mathrm{LDL}$ at week 4 was lower than that at weeks $28(\mathrm{P}=0.0454)$ and 52 (P=0.0373); and LDL at weeks $8,12,16,20$ and 24 was lower than that after the end of treatment (weeks 28,36 , and 52; week 8 vs. 28, $\mathrm{P}=0.0291$, week 8 vs. 36, $\mathrm{P}=0.0149$; week 8 vs. 52 , $\mathrm{P}=0.0134$, week 12 vs. $28, \mathrm{P}=0.0291$, week 12 vs. $36, \mathrm{P}=0.0149$; week 12 vs. 52 , $\mathrm{P}=0.0061$, week 16 vs. 28 , $\mathrm{P}=0.0212$; week 16 vs. 36 , $\mathrm{P}=0.0162$; week 16 vs. $52, \mathrm{P}=0.0170$, week 20 vs. $28, \mathrm{P}=0.0010$, week 20 vs. $36, \mathrm{P}=0.0396$; week 20 vs. $52, \mathrm{P}=0.0338$; week 24 vs. 28 , $\mathrm{P}=0.0013$; week 24 vs. 36 , $\mathrm{P}=0.0111$, week 24 vs. 52, $\mathrm{P}=0.0308$ ). In the no change group: $\mathrm{LDL}$ at week 0 was lower than that at weeks $28-52$ (week $28, \mathrm{P}=0.0067$; week $36, \mathrm{P}=0.0001$ and week 52 , $\mathrm{P}<0.0001$ ); LDL at weeks $4-24$ was lower than that at weeks 28,36 and 52 (week 4 vs. $28, \mathrm{P}=0.0030$, week 4 vs. $36, \mathrm{P}=0.0002$, week 4 vs. 52 , $\mathrm{P}<0.0001$; week 8 vs. $24, \mathrm{P}=0.0117$, week 8 vs. $36, \mathrm{P}=0.0002$, week 8 vs. 52 , $\mathrm{P}<0.0001$, week 12 vs. $28, \mathrm{P}=0.0006$; week 12 vs. 36 , $\mathrm{P}=0.0016$; week 12 vs. 52 , $\mathrm{P}=0.0018$; week 16 vs. $28, \mathrm{P}=0.0005$; week 16 vs. $36, \mathrm{P}=0.0019$, week 16 vs. 52 , $\mathrm{P}=0.0065$; week 20 vs. $28, \mathrm{P}=0.0033$, week 20 vs. $36, \mathrm{P}=0.0006$; week 20 vs. 52, $\mathrm{P}=0.0132$; week 24 vs. $28, \mathrm{P}=0.0018$; week 24 vs. $36, \mathrm{P}=0.0012$; week 24 vs. 52; $\mathrm{P}=0.0031$ ); and $\mathrm{LDL}$ at week 36 was lower than that at week $52(\mathrm{P}=0.0279)$. (C) Trends of HDL concentration in all patients. No significant differences were identified at any time points. (D) Trends of TG concentration in all patients. No significant differences were identified at any time points. (E) BMI and (F) HOMA-IR were compared at weeks 0 and 52. No significant differences were identified at any time points. (G) Hemoglobin A1c was compared at weeks 0, 36 and 52. No significant differences were identified at any time points. DAA, direct acting anti-virals; HDL, high-density lipoprotein; LDL, low-density lipoprotein; TG, triglyceride; BMI, body mass index; HOMA-IR, homeostasis model assessment of insulin resistance; HbAlc, hemoglobin Alc.

weeks 0 and 4 to week 52 was also associated with relative miR122 at week 52, which was indicated to be significant for LDL/HDL increase between weeks 4 and 52 (Fig. 2C and D, and Table III). Relative miR122 at week 52 was not associated with increased HDL, TG or total cholesterol (Table III).

Finally, the variation of serum PCSK9 in 30 patients was measured from the start of DAA treatment to 52 weeks thereafter (Fig. 3). The lower detection limit of PCSK9-A was $32 \mathrm{ng} / \mathrm{ml}$, and therefore concentrations under the detection limit were considered as $32 \mathrm{ng} / \mathrm{ml}$. The most noticeable feature was the variation of PCSK9 at week 4. At week 4, PCSK9-A was lower than that at any other period (Fig. 3A), and PCSK9-I was the highest (Fig. 3C). In 10 patients, PCSK9-A at week 4 was below the lower detection limit. PCSK9-A at week 52 was higher than that during the treatment period (Fig. 3A), but PCSK9-I at week 52 did not markedly differ from the other time points, with the exception of the level at week 4 (Fig. 3C). At the start of treatment, PCSK9-A was higher in 
Table II. Changes in metabolic markers from the beginning of direct acting anti-virals treatment (week 0), to 12 weeks after the end of treatment (week 36) and 26 weeks after the end of treatment (week 52).

\begin{tabular}{lcccr}
\hline Marker & Week 0 (SD) & Week 36 (SD) & Week 52 (SD) & P-value \\
\hline BMI $(\mathrm{kg} / \mathrm{m} / \mathrm{m})$ & $22.95(4.907)$ & $\mathrm{NT}$ & $22.9(5.221)$ & 0.9765 \\
Insulin $(\mu \mathrm{IU} / \mathrm{ml})$ & $10.99(5.359)$ & $\mathrm{NT}$ & $10.1(3.941)$ & 0.2038 \\
C-peptide $(\mathrm{ng} / \mathrm{ml})$ & $2.39(0.787)$ & $\mathrm{NT}$ & $2.197(0.745)$ & 0.4162 \\
FPG $(\mathrm{mg} / \mathrm{dl})$ & $103.12(16.930)$ & $\mathrm{NT}$ & $104.82(14.832)$ & 0.2803 \\
HOMA-IR & $2.87(1.659)$ & $\mathrm{NT}$ & $2.658(1.215)$ & 0.2704 \\
HOMA- $\beta$ & $106.6(53.340)$ & $\mathrm{NT}$ & $93.08(53.350)$ & 0.0501 \\
CPI & $2.316(0.835)$ & $\mathrm{NT}$ & $2.094(0.708)$ & 0,2987 \\
HbA1c $(\%)$ & $5.536(0.510)$ & $5.624(0.463)$ & $5.597(0.468)$ & 0.1664 \\
TC $(\mathrm{mg} / \mathrm{dl})$ & $178.8(33.811)$ & $216.9(42.673)$ & $208.1(34.780)$ & $<0.0001$ \\
LDL $(\mathrm{mg} / \mathrm{dl})$ & $101.1(24.912)$ & $129.3(35.253)$ & $126.1(27.781)$ & $<0.0001$ \\
HDL $(\mathrm{mg} / \mathrm{dl})$ & $56.71(17.623)$ & $58.89(15.170)$ & $59.89(17.331)$ & 0.3466 \\
Triglyceride $(\mathrm{mg} / \mathrm{dl})$ & $110.5(48.710)$ & $114.1(56.672)$ & $119.0(57.651)$ & 0.3625 \\
TG/HDL & $2.279(1.578)$ & $2.192(1.422)$ & $2.344(1.736)$ & 0.7965 \\
LDL/HDL & $1.934(0.723)$ & $2.375(0.967)$ & $2.305(0.911)$ & 0.1150 \\
\hline
\end{tabular}

The data described the mean (SD). All metabolic markers were evaluated following overnight fasting. Measurement techniques for total cholesterol, HOMA-IR, HOMA- $\beta$ and CPI are described in the methods. Laboratory result variables were compared using Student's-test (BMI, insulin, C-peptide, FPG, HOMA-IR, HOMA- $\beta$ and CPI) and one-way ANOVA (HbA1c, total cholesterol, LDL, HDL, triglyceride TG/HDL and LDL/HDL). P-values presented are the overall P-values; multiple comparisons were not performed in the ANOVA. BMI, body mass index; CPI, C-peptide index; FBG, fasting plasma glucose; HbA1c, hemoglobin A1c; TG, triglyceride; TC, total cholesterol; HDL, high-density lipoprotein; LDL, low-density lipoprotein; HOMA-IR, homeostasis model assessment of insulin resistance; HOMA- $\beta$, homeostasis model assessment of insulin secretion; ANOVA, analysis of variance; NT, not tested; SD, standard devation.

Table III. Association between relative microRNA122 at week 52 and increased lipids.

\begin{tabular}{lrc}
\hline Increase rate of PCSK9-A & $\mathrm{R}$ & P-value \\
\hline Week 4-52 & & \\
LDL & 0.339 & 0.0723 \\
HDL & -0.208 & 0.2243 \\
TG & -0.091 & 0.7817 \\
TC & 0.172 & 0.4325 \\
LDL/HDL & 0.547 & 0.0021 \\
Week 0-52 & & \\
LDL & 0.082 & 0.7521 \\
HDL & -0.267 & 0.3321 \\
TG & 0.284 & 0.3081 \\
TC & 0.026 & 0.7568 \\
LDL/HDL & 0.325 & 0.0923 \\
\hline
\end{tabular}

Correlation was evaluated by Pearson's correlation coefficient (R). HDL, high-density lipoprotein; LDL, low-density lipoprotein; TG, triglycerides; TC, total cholesterol.

the upregulation group than that in the no change group, and at week 36, PCSK9-A was moderately higher in the upregulation group than that in the no change group (Fig. 3B). Meanwhile, PCSK9-I at each time point did not differ between the groups (Fig. 3D). An association between PCSK9-A and lipids over weeks 0 and 52 was not detected (Table IV).
A

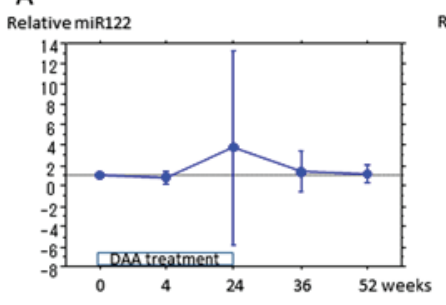

B

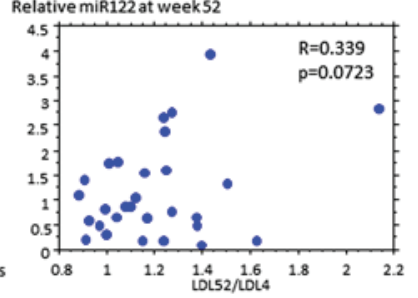

C
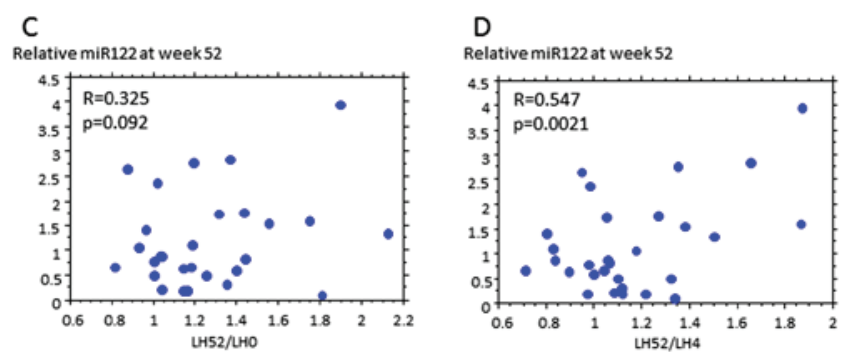

Figure 2. Relative serum miR122 is marginally associated with an increase in LDL. The serum miR122 in 30 of the 39 patients was examined at weeks 0,4 , 24,36 and 52. (A) Relative miR122 at each point fluctuated during the observation period but the differences were not significant. (B) Relative miR122 at week 52 had a positive but non-significant correlation with increased LDL at weeks 4-52. Rate of increase (y-axis) was calculated by the following ratio: LDL at week 52/LDL at week 4. (C and D) Relative miR122 at week 52 had some positive correlation with an increase in LDL/HDL (LH) rate at weeks (C) 0-52 and (D) 4-52. LH rate was calculated by the following ratio: LDL/HDL at the indicated time. miR122, microRNA122; LDL, low-density lipoprotein; HDL, high-density lipoprotein; DAA, direct acting anti-virals.

Relative miR 122 was positively correlated with an increase of PCSK9-A over several time frames (Table V). Relative 


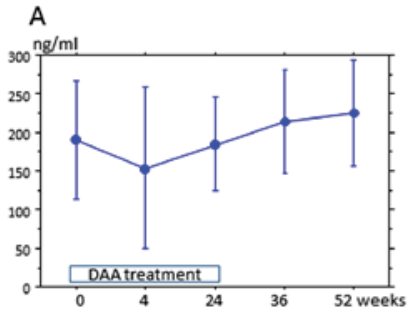

\section{B}
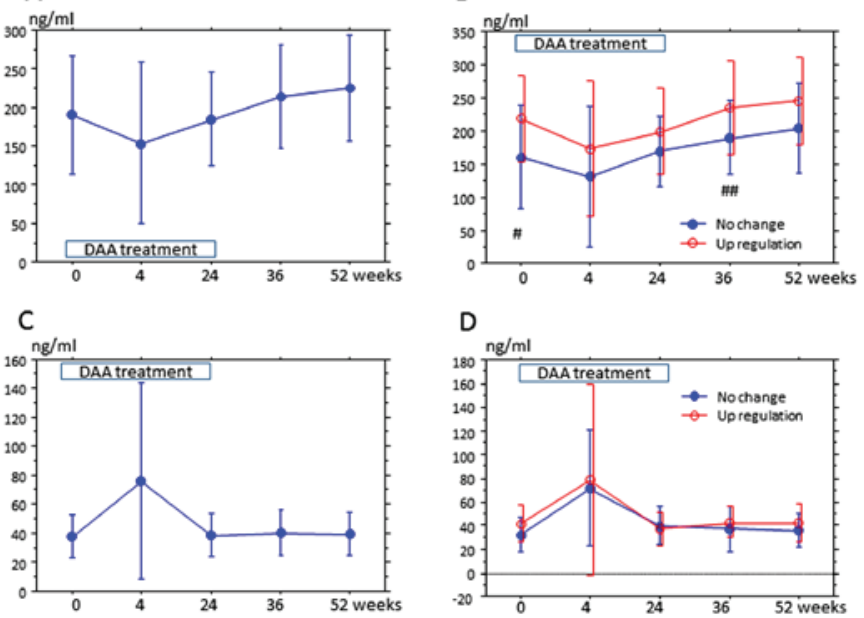

Figure 3. Serum PCSK9 is associated with upregulation of LDL at 52 weeks after treatment. Serum PCSK 9 was examined in 30 of 39 patients at 0,4 , 24, 36 and 52 weeks. The $y$-axis is the mean PCSK9 concentration (ng/ml), and the $\mathrm{x}$-axis is the time after the start of treatment. Error bars represent the standard deviation. (A and B) The trends of PCSK9-A; (C and D) the trends of PCSK9-I. (A) Compared with other time points, PCSK9-A at week 4 was significantly lower (week $0, P=0.0492$; week $24, \mathrm{P}=0.046$; week 36 , $\mathrm{P}=0.046$ and week 52, $\mathrm{P}=0.0111)$. $\mathrm{PCSK} 9-\mathrm{A}$ at week 52 was higher than that at weeks $0(\mathrm{P}=0.0184), 4(\mathrm{P}=0.0009)$ and $24(\mathrm{P}=0.0038)$; these differences were also statistically significant. (B) In the upregulation group, PCSK9-A at week 4 was lower than that at week $0(\mathrm{P}=0.0725)$, week $36(\mathrm{P}=0.046)$, and week $52(\mathrm{P}=0.0111)$; additionally, PCSK9-A at week 24 was lower than that at weeks $36(\mathrm{P}=0.0488)$ and $52(\mathrm{P}=0.0457)$. In the no change group, PCSK9-A at week 52 was higher than that at weeks $0(P=0.0725), 4(P=0.0399)$ and 24 $(\mathrm{P}=0.0457)$. $\mathrm{PCSK} 9-\mathrm{A}$ at week 0 in the upregulation group was higher than that in the no change group $\left({ }^{*} \mathrm{P}=0.0413\right)$, and PCSK9-A at week 36 in the upregulation group was higher than that in the no change group $\left({ }^{\# \prime} \mathrm{P}=0.0697\right)$ (C) PCSK9-I at week 4 was higher than that at weeks $0(\mathrm{P}=0.0055), 24$ $(\mathrm{P}=0.0073)$ and $36(\mathrm{P}=0.0099)$; these values were statistically significant. (D) In the upregulation group, PCSK9-I at week 4 was higher than that at weeks $0(\mathrm{P}=0.09), 24(\mathrm{P}=0.0568)$ and $52(\mathrm{P}=0.0962)$. In the no change group, PCSK9-I at week 4 was higher than that at weeks $0(\mathrm{P}=0.0159), 24$ $(\mathrm{P}=0.0557), 36(\mathrm{P}=0.031)$ and $52(\mathrm{P}=0.0962)$. At each time point, PCSK9-I was not significantly altered between the no change and upregulation groups. PCSK9-A/I, protein convertase subtilisin/kexin 9-active/inactive; LDL, low-density lipoprotein. DAA, direct acting anti-virals.

miR122 at week 4 was associated with an increase in PCSK9-A over 0-36 and 0-52 weeks from the start of treatment $(\mathrm{R}=0.426$, $\mathrm{P}=0.0112$ and $\mathrm{R}=0.544, \mathrm{P}=0.0025$, respectively). Relative miR122 at week 52 was also positively correlated with an increase in PCSK9-A from week 0 to $4(\mathrm{R}=0.396, \mathrm{P}=0.04)$.

\section{Discussion}

In the present study, LDL in patients with $\mathrm{HCV} 1 \mathrm{~b}$ was elevated by DAA treatment from 4 weeks after the start of treatment to 6 months after the end of treatment. Body weight, HDL, TG and insulin resistance were not altered during the 1-year period including DAA treatment. HCV modulates cellular lipid metabolism to enhance self-replication (4). HCV infection has also been associated with reduced serum cholesterol and $\beta$-lipoprotein levels; upon successful antiviral IFN treatment, cholesterol and $\beta$-lipoprotein levels were restored to normal, which suggested that HCV gene expression was responsible for the alteration (24). DAA treatment, but not IFN-based treatment, may also cause elevation of LDL in HCV1b-cleared patients $(9,10)$. A previous study (7) reported that $\mathrm{HCV}$
Table IV. Association between PCSK9 and lipids.

\section{R P-value}

PCSK9-A at week 0

LDL

$-0.045$

0.8193

HDL

$-0.045$

0.6117

TG

$-0.091$

0.4769

LDL/HDL

0.003

0.9873

PCSK9-A at week 52

LDL

$0.167 \quad 0.6724$

HDL

$0.021 \quad 0.6694$

TG

$0.082 \quad 0.5480$

LDL/HDL

$0.110 \quad 0.5817$

PCSK9-A increase rate over weeks 0-52

LDL

$-0.210 \quad 0.1367$

HDL

$-0.308 \quad 0.1145$

TG

$0.130 \quad 0.3332$

LDL/HDL

$0.115 \quad 0.4553$

Correlation was evaluated by Pearson's correlation coefficient (R). HDL, high-density lipoprotein; LDL, low-density lipoprotein; TG, triglycerides; PCSK9-A, protein convertase subtilisin/kexin 9-active.

Table V. Association between relative miR122 and PCSK9-A levels.

\begin{tabular}{lccc}
\hline $\begin{array}{l}\text { Increase rate of } \\
\text { PCSK9-A }\end{array}$ & Relative miR122 & $\mathrm{R}$ & P-value \\
\hline From week 0 to 52 & 4 & 0.476 & 0.0112 \\
24 & 0.239 & 0.2327 & \\
36 & 0.216 & 0.2827 & \\
52 & 0.126 & 0.5362 & \\
From week 0 to 36 & 4 & 0.544 & 0.0028 \\
24 & 0.304 & 0.1243 & \\
36 & 0.244 & 0.2242 & \\
52 & 0.156 & 0.4421 & \\
From week 0 to 24 & 4 & 0.348 & 0.0751 \\
24 & 0.355 & 0.0693 & \\
36 & 0.244 & 0.2217 & \\
52 & 0.036 & 0.8584 & \\
From week 0 to 4 & 4 & 0.159 & 0.4333 \\
24 & -0.151 & 0.4561 & \\
36 & 0.213 & 0.2895 & \\
52 & 0.396 & 0.0400 & \\
& & &
\end{tabular}

Correlation was evaluated by Pearson's correlation coefficient. miR122, microRNA122; PCSK9-A, protein convertase subtilisin/kexin 9-active.

genotype 1 patients with SVR receiving IFN-based treatment had elevated levels of TG, TC and LDL, but stable levels of FPG, insulin and HOMA-IR. In particular, HCV genotype 1 patients with SVR and no insulin resistance developed elevated 
TG and insulin resistance (7). In future, variations in the lipid profile caused by IFN and DAA treatment should be evaluated over long term follow-up periods.

Several mechanisms associated with elevated LDL and HCV clearance have been reported. HCV suppression during sofosbuvir/ribavirin restored distal sterol metabolism, which indicated viral interference with de novo lipogenesis or selective retention by hepatocytes (8). The authors also observed an increase in lanosterol sterol metabolite level in $\mathrm{HCV}$ genotype 3 infection, but not genotype 2 infection, at 12 weeks after the start of treatment, which further supported genotype-specific regulation (8). In another study, clearance of HCV using an IFN-free antiviral regimen resulted in rapid changes in peripheral and intrahepatic metabolic pathways, which implicated a direct effect of $\mathrm{HCV}$ replication on lipid homeostasis (9). Hashimoto et al (10) reported that the increased rate of LDL during the early period of sofosbuvir/ledipasvir treatment was associated with a decrease in $\mathrm{HCV}$ core protein. Collectively these reports have indicated that $\mathrm{HCV}$ inhibits production of cholesterol, and that clearance of HCV may contribute to cholesterol re-production. It may be speculated that the elevation in LDL following DAA treatment in the present cohort may also have been caused by the clearance of HCV. To examine the mechanism of this, miR122 and PCSK9 were detected in serum.

Alterations in miR122 have been established to affect important regulatory enzymes involved cholesterol biosynthesis (3-hydroxy-3-methylglutaryl-CoA reductase), very-LDL secretion (microsomal triglyceride transfer protein) and fatty acid synthesis (sterol regulatory element-binding transcription factor 1, fatty acid synthase, acetyl-CoA-carboxylase 1 and 2 and stearoyl-CoA desaturase). As none of these enzymes are believed to be direct targets of miR122, the mechanism by which it affects lipid metabolism remain unknown (25). Antagonism of miR122 in chimpanzees by miravirsen (SPC3649) led to markedly lowered serum cholesterol in the high-dose group (26). Our previous report (27) revealed that high expression of miR122 in liver at the start of interferon treatment was associated SVR. Previous multivariate analysis has indicated that miR122 is an independent predictor of SVR (26). miR122 protects the 5 ' terminal viral sequences from nucleolytic degradation or from inducing an innate response to the RNA terminus (28), and also acts in an unconventional fashion to stabilize HCV-RNA and slow its decay: an expansion of the usual repertoire of mechanisms by which miRNAs modulate gene expression (29). In one study, IFN- $\beta$ treatment for $30 \mathrm{~min}$ led to a significant reduction in the expression of liver-specific miR122 in HCV non-infected HuH-7 cells (30); by contrast, treatment with polyethylene glycolylated IFN- $\alpha$ for $4 \mathrm{~h}$ in HCV infected patients did not lead to a reduction in the expression of miR122 in liver biopsy samples (31). Our group previously reported on a significant positive correlation between the serum and hepatic levels of miR122 (13). The current study did not determine any significant differences in relative serum miR122 at each time period; however increased LDL and relative miR122 levels were somewhat correlated. To our knowledge, it has not been confirmed whether DAA treatments induce variations in serum miR122 in SVR patients. Since antagonism of miR122 can induce the suppression of HCV replication and cholesterol synthesis (26), it may be speculated that upregulation of miR122 in hepatocytes strengthens lipogenesis and thus elevates levels of LDL in serum. However, the mechanism by which HCV clearance increases miR122 is unknown.

Circulating mature PCSK9 (PCSK9-A) has the ability to degrade cell-surface LDLR, which regulates the levels of circulating LDL, while furin-cleaved PCSK9 (PCSK9-I) is the inactive form (32). Here, DAA treatment decreased PCSK9-A at week 4, while causing an increase in PCSK9-I. At the start of treatment, PCSK9-A in the LDL upregulation group was higher than that in the no change group. Acute clearance of $\mathrm{HCV}$ infection in the liver (at week 4) has been reported to induce an increase in cholesterol synthesis, and PCSK9-A was downregulated to reduce LDL (33). However, it may be speculated that continuous elevated LDL (24, 26 and 52 weeks after the start of DAA) induced recovery of PCSK9-A. HCV downregulates PCSK9 at the protein level (16); therefore, PCSK9-A may be returned to normal levels by HCV clearance. Since patients in the LDL upregulation group had a higher level of PCSK9-A at the start of DAA, it is likely that at 36 weeks later, downregulated LDLR levels led to increased levels of LDL. Increased PCSK9 levels are associated with metabolic disease (34), atherosclerosis (35) and hepatic steatosis (36). However, there appeared to be a lack of reports on the relationship between miR122 and PCSK9. In the current study, relative miR122 at week 4 was associated with an increase in PCSK9-A at 0 to 36 weeks and 0 weeks to the end point. Interestingly, changes in miR122 occurred prior to changes in PCSK9-A; future exploration of the associated mechanism in hepatocytes would be of significance. Additionally, LDLRs are the most effective components for LDL metabolism along with PCSK9-A $(32,33)$. However, LDLR levels were not evaluated in the current study. In future studies, LDLR expression should be investigated for the evaluation of mechanisms resulting in the elevation of LDL following DAA treatment.

In conclusion, DAA treatment for $\mathrm{HCV}$ resulted in elevated LDL levels, but no changes in HDL, TG, insulin resistance or body weight. Relative miR122 and PCSK9-A in serum appeared to have some association with the upregulation of LDL. Since both miR122 and PCSK9 had association with cholesterol mechanism and HCV replication, it was speculated that clearance of $\mathrm{HCV}$ influenced the increase in LDL through variations in miR122 and PCSK9-A. Increased LDL/HDL ratio (37) and PCSK9 (35) are established risk factors for atherosclerosis. A previous report revealed that there are lower levels of LDL-cholesterol and a reduced intima-media thickness (IMT) in HCV patients in comparison with a healthy population (38). Thus, following SVR, it is possible that elevated LDL-cholesterol may increase the IMT. Additionally, the known atherosclerotic markers of hepatic steatosis (39), IMT $(38,40)$ and small-dense LDL $(40)$ in patients with SVR should also be evaluated in the future.

\section{Acknowledgements}

Not applicable.

\section{Funding}

No funding was received. 


\section{Aavailability of data and materials}

The datasets used and/or analysed during the current study are available from the corresponding author on reasonable request.

\section{Authors' contributions}

TI wrote the paper, analyzed the data, and designed the study. NT, HM, SM, JN and YT made substantial contributions to the acquisition of data. YM, HA, TH, HY, RU, NH, SN, HT, SS and $\mathrm{KN}$ made substantial contributions to interpreting the data.

\section{Ethics approval and consent to participate}

Informed consent was obtained from each patient included in the study approval of the study by the Human Research Ethics Committee of Nagasaki Harbor Medical Center (approval no. NIRB 1609002).

\section{Patient consent for publication}

Not applicable.

\section{Competing interests}

The authors declare that they have no competing interests.

\section{References}

1. Negro F: Abnormalities of lipid metabolism in hepatitis $\mathrm{C}$ virus infection. Gut 59: 1279-1287, 2010.

2. Cacoub P, Comarmond C, Domont F, Savey L, Desbois AC and Saadoun D: Extrahepatic manifestations of chronic hepatitis C virus infection. Ther Adv Infect Dis 3: 3-14, 2016.

3. Ferri C, Sebastiani M, Giuggioli D, Colaci M, Fallahi P, Piluso A, Antonelli $\mathrm{A}$ and Zignego AL: Hepatitis $\mathrm{C}$ virus syndrome: $\mathrm{A}$ constellation of organ- and non-organ specific autoimmune disorders, B-cell non-Hodgkin's lymphoma, and cancer. World J Hepatol 7: 327-343, 2015

4. Syed GH, Amako Y and Siddiqui A: Hepatitis C virus hijacks host lipid metabolism. Trends Endocrinol Metab 21: 33-40, 2010.

5. Chayama K, Takahashi S, Toyota J, Karino Y, Ikeda K, Ishikawa $\mathrm{H}$, Watanabe $\mathrm{H}$, McPhee F, Hughes $\mathrm{E}$ and Kumada $\mathrm{H}$ : Dual therapy with the nonstructural protein $5 \mathrm{~A}$ inhibitor, daclatasvir, and the nonstructural protein 3 protease inhibitor, asunaprevir, in hepatitis $\mathrm{C}$ virus genotype $1 \mathrm{~b}$-infected null responders. Hepatology 55: 742-748, 2012.

6. Wang HL, Lu X, Yang X and Xu N: Effectiveness and safety of daclatasvir plus asunaprevir for hepatitis $C$ virus genotype $1 b$ : Systematic review and meta-analysis. J Gastroenterol Hepatol 32 45-52, 2017.

7. Chang ML, Tsou YK, Hu TH, Lin CH, Lin WR, Sung CM, Chen TH, Cheng ML, Chang KC, Chiu C, et al: Distinct patterns of the lipid alterations between genotype 1 and 2 chronic hepatitis $\mathrm{C}$ patients after viral clearance. PLoS One 9: e104783, 2014.

8. Younossi ZM, Stepanova M, Estep M, Negro F, Clark PJ, Hunt S, Song Q, Paulson M, Stamm LM, Brainard DM, et al: Dysregulation of distal cholesterol biosynthesis in association with relapse and advanced disease in CHC genotype 2 and 3 treated with sofosbuvir and ribavirin. J Hepatol 64: 29-36, 2016.

9. Meissner EG, Lee YJ, Osinusi A, Sims Z, Qin J, Sturdevant D, McHutchison J, Subramanian M, Sampson M, Naggie S, et al: Effect of sofosbuvir and ribavirin treatment on peripheral and hepatic lipid metabolism in chronic hepatitis $\mathrm{C}$ virus, genotype 1-infected patients. Hepatology 61: 790-801, 2015.

10. Hashimoto S, Yatsuhashi H, Abiru S, Yamasaki K, Komori A, Nagaoka S, Saeki A, Uchida S, Bekki S, Kugiyama Y, et al Rapid increase in serum low-density lipoprotein cholesterol concentration during hepatitis $\mathrm{C}$ interferon-free treatment. PLoS One 11: e0163644, 2016.
11. Janssen HL, Reesink HW, Lawitz EJ, Zeuzem S, Rodriguez-Torres M, Patel K, van der Meer AJ, Patick AK, Chen A, Zhou Y, et al: Treatment of HCV infection by targeting microRNA. N Engl J Med 368: 1685-1694, 2013.

12. Esau C, Davis S, Murray SF, Yu XX, Pandey SK, Pear M, Watts L, Booten SL, Graham M, McKay R, et al: miR-122 regulation of lipid metabolism revealed by in vivo antisense targeting. Cell Metab 3: 87-98, 2006.

13. Miyaaki H, Ichikawa T, Kamo Y, Taura N, Honda T, Shibata H, Milazzo M, Fornari F, Gramantieri L, Bolondi L and Nakao K: Significance of serum and hepatic microRNA-122 levels in patients with non-alcoholic fatty liver disease. Liver Int 34: e302-e307, 2013

14. Cunningham D, Danley DE, Geoghegan KF, Griffor MC, Hawkins JL, Subashi TA, Varghese AH, Ammirati MJ, Culp JS, Hoth LR, et al: Structural and biophysical studies of PCSK9 and its mutants linked to familial hypercholesterolemia. Nat Struct Mol Biol 14: 413-419, 2007.

15. Labonté P, Begley S, Guévin C, Asselin MC, Nassoury N, Mayer G, Prat A and Seidah NG: PCSK9 impedes hepatitis C virus infection in vitro and modulates liver CD81 expression. Hepatology 50: 17-24, 2009.

16. Syed GH, Tang H, Khan M, Hassanein T, Liu J and Siddiqui A: Hepatitis C virus stimulates low-density lipoprotein receptor expression to facilitate viral propagation. J Virol 88: 2519-2529, 2014.

17. Bridge SH, Sheridan DA, Felmlee DJ, Crossey MM, Fenwick FI, Lanyon CV, Dubuc G, Seidah NG, Davignon J, Thomas HC, et al: PCSK9, apolipoprotein E and lipoviral particles in chronic hepatitis $\mathrm{C}$ genotype 3 : evidence for genotype-specific regulation of lipoprotein metabolism. J Hepatol 62: 763-770, 2015.

18. Matthews DR, Hosker JP, Rudenski AS, Naylor BA, Treacher DF and Turner RC: Homeostasis model assessment: Insulin resistance and beta-cell function from fasting plasma glucose and insulin concentrations in man. Diabetologia 28: 412-419, 1985.

19. Asano T, Kawamura M, Watanabe T, Abe M, Chin R, Miyazaki S and Hirata Y: Indices of urinary and serum C-peptide corrected with fasting plasma glucose for decision-making of insulin therapy in type 2 diabetes-validation and comparison. J Jpn Diabetes Soc 51: 759-763, 2008.

20. DeLong DM, DeLong ER, Wood PD, Lippel K and Rifkind BM: A comparison of methods for the estimation of plasma low- and very low-density lipoprotein cholesterol. The Lipid Research Clinics Prevalence Study. JAMA 256: 2372-2377, 1986.

21. Hori M, Ishihara M, Yuasa Y, Makino H, Yanagi K, Tamanaha T, Kishimoto I, Kujiraoka T, Hattori H and Harada-Shiba M: Removal of plasma mature and furin-cleaved proprotein convertase subtilisin/kexin 9 by low-density lipoprotein-apheresis in familial hypercholesterolemia: Development and application of a new assay for PCSK9. J Clin Endocrinol Metab 100: E41-E49, 2015.

22. Livak KJ and Schmittgen TD: Analysis of relative gene expression data using real-time quantitative PCR and the 2(-Delta Delta C(T)) method. Methods 25: 402-408, 2001.

23. Sohn W, Kim J, Kang SH, Yang SR, Cho JY, Cho HC, Shim SG and Paik YH: Serum exosomal microRNAs as novel biomarkers for hepatocellular carcinoma. Exp Mol Med 47: e184, 2015.

24. Negro F and Sanyal AJ: Hepatitis C virus, steatosis and lipid abnormalities: clinical and pathogenic data. Liver Int 29 (Suppl 2): 26-37, 2009.

25. Rotllan N,Price N,Pati P, Goedeke L and Fernández-Hernando C: microRNAs in lipoprotein metabolism and cardiometabolic disorders. Atherosclerosis 246: 352-360, 2016.

26. Lanford RE, Hildebrandt-Eriksen ES, Petri A, Persson R, Lindow M, Munk ME, Kauppinen S and Ørum H: Therapeutic silencing of microRNA-122 in primates with chronic hepatitis C virus infection. Science 327: 198-201, 2010.

27. Kamo Y, Ichikawa T, Miyaaki H, Uchida S, Yamaguchi T, Shibata H, Honda T, Taura N, Isomoto H, Takeshima F and Nakao K: Significance of miRNA-122 in chronic hepatitis C patients with serotype 1 on interferon therapy. Hepatol Res 45: 88-96, 2015.

28. Machlin ES, Sarnow P and Sagan SM: Masking the 5' terminal nucleotides of the hepatitis $\mathrm{C}$ virus genome by an unconventional microRNA-target RNA complex. Proc Natl Acad Sci U S A 108: 3193-3198, 2011.

29. Shimakami T, Yamane D, Jangra RK, Kempf BJ, Spaniel C, Barton DJ and Lemon SM: Stabilization of hepatitis C virus RNA by an Ago2-miR-122 complex. Proc Natl Acad Sci U S A 109: 941-946, 2012. 
30. Pedersen IM, Cheng G, Wieland S, Volinia S, Croce CM, Chisari FV and David M: Interferon modulation of cellular microRNAs as an antiviral mechanism. Nature 449: 919-922, 2007.

31. Sarasin-Filipowicz M, Krol J, Markiewicz I, Heim MH and Filipowicz W: Decreased levels of microRNA miR-122 in individuals with hepatitis $\mathrm{C}$ responding poorly to interferon therapy. Nat Med 15: 31-33, 2009.

32. Benjannet S, Rhainds D, Hamelin J, Nassoury N and Seidah NG: The proprotein convertase (PC) PCSK9 is inactivated by furin and/or PC5/6A: Functional consequences of natural mutations and post-translational modifications. J Biol Chem 281: 30561-30572, 2006

33. Lagace TA: PCSK9 and LDLR degradation: Regulatory mechanisms in circulation and in cells. Curr Opin Lipidol 25 387-393, 2014.

34. Girona J, Ibarretxe D, Plana N, Guaita-Esteruelas S, Amigo N, Heras $M$ and Masana L: Circulating PCSK9 levels and CETP plasma activity are independently associated in patients with metabolic diseases. Cardiovasc Diabetol 15: 107, 2016.

35. Wang S, Cheng ZY, Zhao ZN, Quan XQ, Wei Y, Xia DS, Li JQ and Hu JL: Correlation of serum PCSK9 in CHD patients with the severity of coronary arterial lesions. Eur Rev Med Pharmacol Sci 20: 1135-1139, 2016.
36. Ruscica M, Ferri N, Macchi C, Meroni M, Lanti C, Ricci C, Maggioni M, Fracanzani AL, Badiali S, Fargion S, et al: Liver fat accumulation is associated with circulating PCSK9. Ann Med 48: 384-391, 2016

37. Tamada M, Makita S, Abiko A, Naganuma Y, Nagai M and Nakamura M: Low-density lipoprotein cholesterol to high-density lipoprotein cholesterol ratio as a useful marker for early-stage carotid atherosclerosis. Metabolism 59: 653-657, 2010.

38. Miyajima I, Kawaguchi T, Fukami A, Nagao Y, Adachi H, Sasaki S, Imaizumi T and Sata M: Chronic HCV infection was associated with severe insulin resistance and mild atherosclerosis: A population-based study in an HCV hyperendemic area. J Gastroenterol 48: 93-100, 2013.

39. Negro F: Facts and fictions of HCV and comorbidities: Steatosis, diabetes mellitus, and cardiovascular diseases. J Hepatol 61 (Suppl 1): S69-S78, 2014.

40. Shen H, Xu L, Lu J, Hao T, Ma C, Yang H, Lu Z, Gu Y, Zhu T and Shen G: Correlation between small dense low-density lipoprotein cholesterol and carotid artery intima-media thickness in a healthy Chinese population. Lipids Health Dis 14: 137, 2015. 